\title{
Impact of Verbal and Braille Text Oral Hygiene Instructions on Visually Impaired Individuals: A Randomized Clinical Trial
}

\author{
Hytham N Fageeh ${ }^{1}$, Manawar A Mansour ${ }^{2}$, Hussam M Muyidi ${ }^{3}$, Abu Bakr Ahmed $^{4}$, Sameer J Ogayshi ${ }^{5}$, \\ Reghunathan S Preethanath ${ }^{6}$
}

\begin{abstract}
Aim: To assess the oral hygiene knowledge and compare the effect of verbal oral hygiene instructions with that of textual Braille instructions on the periodontal health status of Arabic-speaking visually impaired individuals.

Materials and methods: Sixty individuals (age, 8-57 years) with visual impairment were randomly recruited and divided into two intervention groups ( $n=30$ each) based on the mode of oral hygiene instructions: verbal and Braille. A questionnaire with 15 close-ended questions was used to assess knowledge, attitude, and practices related to oral health. The periodontal status (using oral hygiene, gingival, and plaque scores) was examined, and oral prophylaxis was performed. After 3 months, reassessments were conducted to evaluate the oral hygiene and overall knowledge in each group.

Results: Baseline responses showed low knowledge and poor attitudes toward self-care of oral health among the subjects in both groups. After 3 months of follow-up, the mean overall knowledge of the remaining 53 participants was significantly $(p<0.05)$ increased from $(3.97 \pm$ 1.33 and $4.21 \pm 1.4)$ to $(5.77 \pm 2.79$ and $11.62 \pm 2.5)$ in the verbal and Braille textual instructions groups, respectively. Significant reductions in oral hygiene, gingival, and plaque scores from baseline were observed in both groups $(p<0.01)$. After 12 weeks, the plaque, calculus, and oral hygiene indices were significantly lower in the Braille group $(n=27)$ when compared with those in the verbal group $(n=26 ; p<0.01)$. There were three dropouts in the Braille group and four dropouts in the verbal group.

Conclusion: This trial demonstrated the effectiveness of using a textual Braille to improve both the knowledge and clinical periodontal indices in visually impaired individuals when compared with that of a verbal intervention alone.

Clinical significance: The study revealed that Braille textural communication can be used as an effective tool to implement oral hygiene instructions in visually impaired individuals.

Keywords: Braille text, Health promotion, Oral hygiene, Visually impaired.

World Journal of Dentistry (2020): 10.5005/jp-journals-10015-1775
\end{abstract}

\section{INTRODUCTION}

Oral health is an important part of general health and can impact the quality of life of the individual. Visual impairment refers to the condition where the eyesight of an individual cannot be restored to normal; the decrease in visual function hinders the ability to conduct the normal activities of daily living. ${ }^{1}$ Individuals with visual impairment face difficulties in maintaining their oral health due to the inability to detect and identify oral disease at an early stage. ${ }^{2}$ A recent systematic review and meta-analysis by Bourne et al. reported that an estimated 36 million people experienced blindness and 405 million people had visual impairment (ranging from mild to severe). ${ }^{3}$ A vast majority of them live in developing countries, including Arabic-speaking countries such as Saudi Arabia. ${ }^{4}$

Good oral health is important to maintain the quality of life of an individual. Therefore, it is important to create awareness about oral health promotion among visually impaired people. The early symptoms of oral diseases that are usually identified through vision might be missed in individuals with visual impairment leading to poor oral health. For example, signs of tooth discoloration and gingival conditions may remain unnoticed in the visually impaired and lead to further deterioration of the oral condition unless informed about the situation and treated on time. Some individuals with visual impairment may have limited manual dexterity which could affect some of their oral hygiene skills, such as toothbrushing and flossing. Studies have shown that oral hygiene in a visually impaired or blind person is worse than that in a normally sighted

\begin{abstract}
1,6Department of Preventive Dental Sciences, College of Dentistry, Jazan University, Kingdom of Saudi Arabia

${ }^{2}$ Department of Prosthetic Dental Sciences, College of Dentistry, Jazan University, Kingdom of Saudi Arabia

${ }^{3-5}$ College of Dentistry, Jazan University, Kingdom of Saudi Arabia

Corresponding Author: Hytham N Fageeh, Department of Preventive Dental Sciences, College of Dentistry, Jazan University, Kingdom of Saudi Arabia, Phone: +966500009316, e-mail: hfageeh@jazanu.edu.sa How to cite this article: Fageeh HN, Mansour MA, Muyidi HM, et al. Impact of Verbal and Braille Text Oral Hygiene Instructions on Visually Impaired Individuals: A Randomized Clinical Trial. World J Dent 2020;11(6):439-445.
\end{abstract}

Source of support: Nil

Conflict of interest: None

individual. 5,6 A recent study conducted in Riyadh, Saudi Arabia, reported inadequate plaque control, extensive gingivitis, and limited access to healthcare providers among visually impaired adults. ${ }^{7}$ A study by Chang and Shih in Taiwan reported that visually impaired children had less knowledge about dental health and did not perform oral hygiene practices as well as sighted students. ${ }^{8}$

The visually impaired rely mostly on sound, speech, and touch. ${ }^{1}$ Hence, it is important to promote the importance of oral health in this population using methods that are easily understood. The provision of oral hygiene instructions is a useful method of oral 
health promotion and should be modified based on the level of impairment using verbal instructions, large bold text, Braille, audio information, or models. ${ }^{9,10}$ Visually impaired individuals depend heavily on their tactile senses. In addition, they respond well to verbal instructions. ${ }^{1}$ Mahantesha et al. demonstrated the beneficial effects of Braille and audio instruction on improving the oral hygiene levels in visually impaired children. ${ }^{11}$ Another recent study comprising 144 visually impaired children reported that the Braille method was more effective than the compressed speech method to provide oral health education. ${ }^{12}$ Khurana et al. reported improvements in the oral hygiene of visually impaired children after using Braille text to provide oral health education when compared with the baseline values. ${ }^{13}$ Chowdary et al. used verbal instructions, Braille text, and the combination of both and reported reductions in plaque and gingival scores among visually impaired children in India. ${ }^{14}$ Furthermore, Krishnakumar et al. reported a significant reduction in plaque scores using the audio-tactile method to impart oral health education. ${ }^{15}$

The importance of utilizing repetition and reinforcement in dental health education programs for school children has been reported. ${ }^{16}$ A study conducted in Turkey reported the effectiveness of repeated oral health education on oral health knowledge and hygiene of visually impaired children aged 7-17 years. ${ }^{17}$ However, despite the importance of providing oral health knowledge to the visually impaired, very little has been done in this regard. More importance is placed on the disability than on oral hygiene in these individuals. ${ }^{6}$ There is a dearth of studies on the teaching of oral hygiene skills to the visually impaired, particularly in Arabicspeaking countries.

This study aimed to assess the knowledge of oral hygiene and to compare the effectiveness of both verbal and textual Braille oral hygiene instructions in improving the periodontal health status of Arabic-speaking individuals with visual impairment.

\section{Materials and Methods}

\section{Trial Design and Clinical Setting}

This randomized trial with a parallel study design and an allocation ratio of 1:1 was carried out at the Periodontics Clinics at the College of Dentistry at Jazan University. Ethical clearance was obtained from the ethical committee of the scientific research committee, College of Dentistry, Jazan University (reference number: CODJU-1731I). The purpose of the study was explained to the participants and written consent was obtained. The study was carried out according to the guidelines of the Helsinki declaration.

\section{Participants}

A total of 72 visually blind individuals between the age group of 8 and 57 years were randomly enrolled from the various blind schools in the province of Jazan, Saudi Arabia. The inclusion criteria for the study were as follows: complete blindness; knew how to read Braille; provided informed consent to participate in the study. Nine individuals did not meet the eligibility criteria and three individuals declined to participate in the study. Hence, a total of 60 visually impaired subjects were finally selected and their knowledge of oral hygiene was assessed.

\section{Randomization}

The patients were then divided into two groups using a simple randomization technique.

A table of random numbers was employed for the simple randomization of the subjects to the educational intervention. To prevent selection bias, a centralized assignment was used as an allocation concealment mechanism. The details of the randomization and recruitment are represented in Flowchart 1.

Group I is comprised of 30 individuals who received verbal oral hygiene instructions and group II is comprised of 30 individuals who received the instructions through a textual Braille.

\section{Baseline Knowledge and Behavior Assessment}

A close-ended questionnaire in the Arabic language was adopted from a study by Fageeh et al., which assessed the effectiveness of oral hygiene instructions in sign language for the hearing impaired. ${ }^{18}$ The questionnaire contained 15 questions designed to assess the knowledge, attitude, and practices related to oral health (Appendix 1). All the questions had multiple choice answers based on information that was presented in the content. A correct answer to the question was given a score of "1" and a wrong

Flowchart 1: Randomization and sample selection used in the study

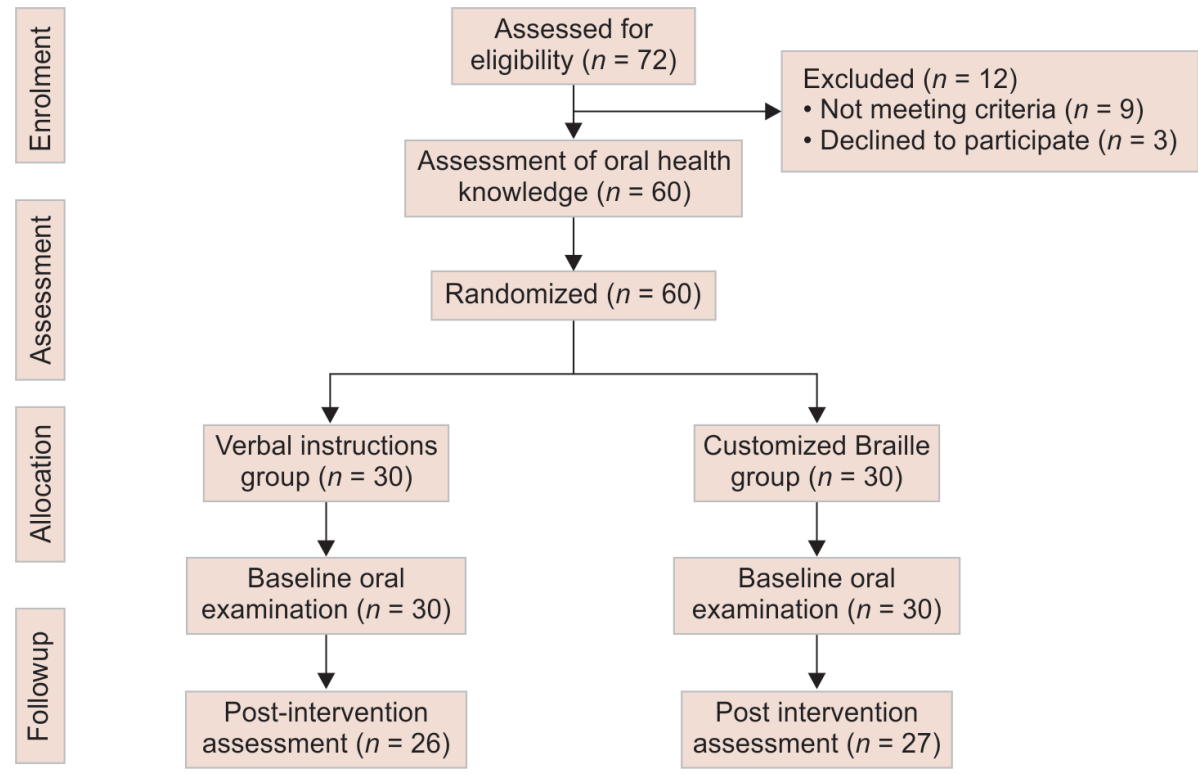


answer was given a score of " 0 ". All answers were evidence-based which are readily available from position papers published by the American Academy of Periodontology (AAP). A knowledge score was calculated for each participant by calculating the number of his correct answers on the questionnaire.

After an interval of 3 months, another questionnaire-based knowledge assessment was conducted for all of the participating subjects. The knowledge score and percentage of correct answers were then compared before and after the intervention for each question. The estimated mean of knowledge was then calculated for each group and compared before and after the intervention. The investigator was blinded to the group assignment in the study and was present with each subject when the questionnaire was being filled out by their accomplice to ensure that they had fully understood the questions in the questionnaire.

\section{Educational Intervention}

Oral health instructions regarding all aspects of hygiene were read out from the customized Braille in Arabic for the subjects in the verbal instructions group. The instructions were delivered by a trained periodontist with at least 4 years of teaching experience. The subjects in the Braille instructions group received a simplified, custom-designed Arabic Braille handout that was read by each one of them after the scaling session. The customized oral hygiene instructions were prepared by experts at the Division of Periodontics and printed into Braille format before the study.

\section{Baseline Oral Assessment}

An oral examination of the periodontal health status was conducted by a single investigator who was masked to the randomization of the subjects. The simplified oral hygiene index (OHI-S by Green and Vermillion), gingival index (GI by Loe and Sillness), and plaque index (PI by Sillness and Loe) were used to assess the baseline oral hygiene, gingival, and plaque indices, respectively. This was followed by full mouth scaling and polishing by another examiner who delivered the oral hygiene instructions verbally or by Braille.

\section{Post-intervention Assessment}

Reassessment of knowledge using the same questionnaire and reevaluation of clinical scores were performed at 3 months by the same investigator who performed the baseline examinations. The investigator was blinded to the group assignment in the study. There were dropouts of four visually impaired individuals in the verbal instructions group and three dropouts in the Braille instructions group. Subsequently, a complimentary prophylaxis session was provided to the subjects.

\section{Statistical Analysis}

The results are presented as mean \pm standard deviation. Chisquare test was used to assess the difference in the distribution of the participants by different grouping factors (qualitative variables). Shapiro-Wilk's test was used to check for the normality of the qualitative data. Differences in these qualitative dependent variables between the two groups (between-group comparisons) were assessed using an independent $t$ test. A paired $t$ test was used for within-group comparisons. Data were analyzed using SPSS software (version 21; IBM, Armonk, New York, USA). A $p$ value of $<0.05$ was considered significant.

\section{Results}

The characteristics of the subjects included in this study are shown in Table 1. A total of 47 males (verbal group, 25; Braille group, 22) and 13 females (verbal group, 6; Braille group, 7) were included in the study. The mean ages of the subjects in the verbal and Braille instruction groups were $23.03 \pm 10.83$ and $22.03 \pm 10.69$ years. No significant differences in mean age or gender distribution were observed between the two groups.

Table 2 shows the mean pre- and post-interventional scores for debris, $\mathrm{Cl}, \mathrm{OHI}-\mathrm{S}, \mathrm{PI}, \mathrm{Gl}$, and overall knowledge were observed in both groups. In the verbal instructions group, significant differences $(p<0.05)$ were observed between the pre- and post-interventional scores for debris $(1.93 \pm 0.28$ vs $0.87 \pm 0.47), \mathrm{Cl}(1.36 \pm 0.32$ vs 0.32

Table 1: Characteristics of the study sample

\begin{tabular}{llllll}
\hline & & \multicolumn{2}{c}{ Group } \\
\cline { 3 - 5 } Variables & All & Verbal $(n=30)$ & Braille $(n=30)$ & $p$ value \\
\hline Gender & Males, $n(\%)$ & $47(78.3)$ & $25(80.6)$ & $22(75.9)$ & 0.758 \\
& Females, $n(\%)$ & $13(21.7)$ & $6(19.4)$ & $7(24.1)$ & \\
Age/years mean \pm SD & & $22.55 \pm 10.68$ & $23.03 \pm 10.83$ & $22.03 \pm 10.69$ & 0.721 \\
\hline
\end{tabular}

$\mathrm{SD}$, standard deviation

Table 2: Interventional measurements (pre and post) of the study variables

\begin{tabular}{|c|c|c|c|c|c|c|}
\hline \multirow[b]{3}{*}{ Variables } & \multicolumn{4}{|c|}{ Groups } & \multirow{2}{*}{\multicolumn{2}{|c|}{$p$ value }} \\
\hline & \multicolumn{2}{|c|}{$\operatorname{Verbal}(n=30)$} & \multicolumn{2}{|c|}{ Braille $(n=30)$} & & \\
\hline & $\begin{array}{l}\text { Pre-interventional } \\
(n=30)\end{array}$ & $\begin{array}{l}\text { Post-interventional } \\
(n=26)\end{array}$ & $\begin{array}{l}\text { Pre-interventional } \\
(n=30)\end{array}$ & $\begin{array}{l}\text { Post-interventional } \\
(n=27)\end{array}$ & Pre & Post \\
\hline Debris & $1.93 \pm 0.28$ & $0.87 \pm 0.47^{*}$ & $1.88 \pm 0.23$ & $0.42 \pm 0.3^{*}$ & 0.512 & $<0.001$ \\
\hline $\mathrm{Cl}$ & $1.36 \pm 0.32$ & $0.32 \pm 0.13^{*}$ & $1.38 \pm 0.34$ & $0.17 \pm 0.11^{*}$ & 0.865 & $<0.001$ \\
\hline $\mathrm{OHI}-\mathrm{S}$ & $3.29 \pm 0.53$ & $1.18 \pm 0.49^{*}$ & $3.26 \pm 0.5$ & $0.59 \pm 0.36^{*}$ & 0.831 & $<0.001$ \\
\hline $\mathrm{PI}$ & $1.39 \pm 0.18$ & $0.47 \pm 0.4^{*}$ & $1.36 \pm 0.18$ & $0.39 \pm 0.35^{*}$ & 0.498 & 0.473 \\
\hline $\mathrm{Gl}$ & $1.69 \pm 0.35$ & $0.39 \pm 0.25^{*}$ & $1.56 \pm 0.32$ & $0.5 \pm 0.42^{*}$ & 0.175 & 0.271 \\
\hline Overall knowledge & $3.97 \pm 1.33$ & $5.77 \pm 2.79 *$ & $4.21 \pm 1.4$ & $11.62 \pm 2.5^{*}$ & 0.5 & $<0.001$ \\
\hline
\end{tabular}

*Denotes that the post-interventional measurements were statistically significant compared to the pre-interventional measurements within each subgroup $\mathrm{Cl}$, calculus index; $\mathrm{Gl}$, gingival index; $\mathrm{OHI}-\mathrm{S}$, simplified oral hygiene index; $\mathrm{Pl}$, plaque index 
$\pm 0.13), \mathrm{OHI}-\mathrm{S}(3.29 \pm 0.53$ vs $1.18 \pm 0.49), \mathrm{PI}(1.39 \pm 0.18$ vs $0.47 \pm$ $0.4)$, and $\mathrm{Gl}(1.69 \pm 0.35$ vs $0.39 \pm 0.25)$. The pre-interventional score for overall knowledge $(3.97 \pm 1.33)$ was significantly lower than the post-interventional score $(5.77 \pm 2.79)$ in this group. Similarly, significant differences in the pre- and post-intervention scores for debris ( $1.88 \pm 0.23$ vs $0.42 \pm 0.3), \mathrm{Cl}(1.38 \pm 0.34$ vs $0.17 \pm 0.11)$, OHI-S $(3.26 \pm 0.5$ vs $0.59 \pm 0.36), \mathrm{Pl}(1.36 \pm 0.18$ vs $0.39 \pm 0.35), \mathrm{Gl}(1.56 \pm$ 0.32 vs $0.5 \pm 0.42)$, and overall knowledge ( $4.21 \pm 1.4$ vs $11.62 \pm 2.5)$ were observed in the Braille group.

Furthermore, the post-interventional scores for debris $(0.42$ \pm 0.3 vs $0.87 \pm 0.47), \mathrm{Cl}(0.17 \pm 0.11$ vs $0.32 \pm 0.13)$, and $\mathrm{OHI}-\mathrm{S}$ $(0.59 \pm 0.36$ vs $1.18 \pm 0.49)$ in the Braille instructions group were significantly $(p<0.001)$ lower than those in the verbal instructions group; alternatively, the score for overall knowledge in this group $(11.62 \pm 2.5$ vs $5.77 \pm 2.79)$ was significantly $(p<0.001)$ higher than that in the verbal instructions group.

The mean differences in the pre- and post-interventional scores for 26 participants ( 4 dropouts in the verbal group and 3 dropouts in the Braille group) debris, OHI-S, and overall knowledge were significantly higher $(p<0.001)$ in the Braille instruction $(-1.03 \pm$ $0.52,-2.03 \pm 0.67$, and $1.77 \pm 2.94$, respectively) when compared with those in the verbal instruction group $(-1.47 \pm 0.36,-2.64 \pm$ 0.57 , and $7.38 \pm 3.29$, respectively; Table 3 ).

These findings indicate that significant differences between the pre- and post-intervention scores for debris, $\mathrm{Cl}, \mathrm{OHI}-\mathrm{S}, \mathrm{PI}$, $\mathrm{Gl}$, and overall knowledge were observed among the visually impaired subjects in both groups. The Braille group presented with significantly lower post-interventional debris, $\mathrm{Cl}$, and $\mathrm{OHI}-\mathrm{S}$ scores and significantly higher overall knowledge than the verbal instructions group. Furthermore, the Braille instruction group presented significantly higher mean differences between the pre- and post-interventional scores for debris, $\mathrm{OHI}-\mathrm{S}$, and overall knowledge than the verbal instruction group.

\section{Discussion}

The present study aimed to ascertain the knowledge of oral health and the effectiveness of using Braille instructions for improving this knowledge among Arabic-speaking visually impaired individuals in the province of Jazan, Saudi Arabia. In addition, the oral health status of the individuals was evaluated.

Similar to the findings of the studies by Khurana et al., ${ }^{13,14}$ significant decreases in the mean $\mathrm{OHI}-\mathrm{S}, \mathrm{PI}$, and $\mathrm{Gl}$ scores were observed before and after the intervention in both groups in the current study. The instructions provided to patients generally include an explanation about the benefits of maintaining good oral hygiene. In addition, various methods of toothbrushing and

Table 3: Measurements of study variables

\begin{tabular}{lrcr}
\hline \multirow{2}{*}{ Variables } & \multicolumn{2}{c}{ Group } & \\
\cline { 2 - 3 } Debris & Verbal $(n=26)$ & Braille $(n=26)$ & p value \\
Cl & $-1.03 \pm 0.52$ & $-1.47 \pm 0.36$ & $\mathbf{0 . 0 0 1}$ \\
OHI-S & $-2.03 \pm 0.36$ & $-1.17 \pm 0.33$ & 0.072 \\
PI & $-0.92 \pm 0.44$ & $-2.64 \pm 0.57$ & $\mathbf{0 . 0 0 1}$ \\
GI & $-1.26 \pm 0.36$ & $-1.07 \pm 0.6$ & 0.679 \\
Overall knowledge & $1.77 \pm 2.94$ & $7.38 \pm 3.29$ & 0.144 \\
\hline
\end{tabular}

$\mathrm{Cl}$, calculus index; $\mathrm{Gl}$, gingival index; $\mathrm{OHI}-\mathrm{S}$, simplified oral hygiene index; $\mathrm{Pl}$, plaque index

Bold fonts, represents statistical significance of values interdental cleaning are demonstrated using visual aids. However, these methods cannot be used for blind or visually impaired patients. A recent study comprising 48 visually impaired children demonstrated the effectiveness of using auditory instruction materials for improving oral hygiene. ${ }^{9}$ The children were divided into two groups and instructions were provided using audio or audio-tactile methods. The children in both groups demonstrated improved oral hygiene with no significant differences between the two groups. Another study conducted with 96 visually impaired children (6-18 years old) demonstrated significant reductions in their plaque scores after the provision of oral health education using the audio-tactile method..$^{10}$ Recently, a study conducted in Bulgaria demonstrated the benefits of providing oral health education to blind children using other modes such as embossed images printed on special microcapsule paper, models of teeth, and audiotapes; significant improvements in the oral hygiene habits of the visually impaired children were reported. ${ }^{11}$

Visual impairment can harm the oral hygiene status of an individual because they cannot see the build-up of calculus and debris in the oral cavity. Visually impaired children have been reported to have poor skills and knowledge about oral hygiene. 8,19 The development of skills in visually impaired children is slow and challenging due to difficulties in orientation and forming spatial concepts. ${ }^{20}$ Parents or caregivers play a major role in assisting children with visual impairment. The instructions must be provided clearly, slowly, and in a repetitive manner. Verbal instructions and tactile methods have been used to improve the toothbrushing habits in these children. ${ }^{6,11,14}$ A recent study evaluated the effects of various sensory input methods (audio, Braille, tooth models, and a combination of all three) on the oral health knowledge and hygiene of 200 blind children aged $8-14$ years. ${ }^{15}$ Significant improvements in mean knowledge scores and reductions in plaque scores were observed in the children who received oral health education using these special methods.

Tactile spatial acuity is known to be enhanced in blind people. ${ }^{21,22} \mathrm{~A}$ recent study evaluated the oral health status and knowledge among visually impaired individuals using Braille and compressed speech and reported a significant increase in the mean knowledge in the Braille instruction group. ${ }^{12}$ Chowdary et al. demonstrated that the combination of the three methods of oral health education was effective in reducing the plaque and gingival scores of 120 visually impaired children in India. ${ }^{14}$ Likewise, Gautam et al. reported that the combination of audio, Braille, and tactile models can be used to effectively disseminate oral health knowledge in visually impaired children. ${ }^{15}$ In the study by Deshpande et al., the combination of Braille and audiotactile performance technique was found to be most effective in teaching oral hygiene methods to 60 visually impaired adolescents in Maharashtra, India. ${ }^{23}$ A recent study by Bhor et al. reported a significant increase in oral health knowledge levels among children who received instructions using Braille in combination with oral health talks when compared with those who received Braille text instructions only. ${ }^{24}$

The current study demonstrated statistically significant reductions in the debris, $\mathrm{OHI}-\mathrm{S}, \mathrm{PI}$, and $\mathrm{Gl}$ scores and a significant increase in overall knowledge among the verbal instruction and Braille instruction groups of visually impaired individuals. Furthermore, Braille instructions appeared to be more effective in improving the overall knowledge about oral health promotion. The estimated mean of knowledge calculated for each group and 
compared before and after the intervention showed a significant increase in overall post-intervention knowledge scores in the verbal and Braille instruction groups. These findings indicate that the use of effective interventional methods can improve the knowledge and the oral health status of individuals with visual impairment.

\section{ConcLusion}

Arabic Braille oral hygiene instructions can immensely improve the knowledge about oral health and hygiene practices among the visually impaired individuals and should be recommended for use in various healthcare centers in Saudi Arabia. The small study group used in the study and the Arabic Braille $\mathrm{OHI}$ which can be used only for a limited population are the main shortcomings of the study. Further studies using a wide population and modifying the language barrier in Braille instructions can be an effective method in improving the oral health status of visually impaired children.

\section{References}

1. Schembri A, Janice Fiske DG. The implications of visual impairment in an elderly population in recognizing oral disease and maintaining oral health. Special Care Dentist 2001;21(6):222-226.

2. Mesfin. SYL, B. F. Blindness-StatPearls-NCBI Bookshelf. 2017.

3. Bourne RRA, Flaxman SR, Braithwaite T, et al. Magnitude, temporal trends, and projections of the global prevalence of blindness and distance and near vision impairment: a systematic review and meta-analysis. Lancet Glob Heal 2017;5(9):e888-e897. DOI: 10.1016/ S2214-109X(17)30293-0.

4. Parrey MUR, Alswelmi FK. Prevalence and causes of visual impairment among Saudi adults. Pak J Med Sci 2017;33(1):167-171.

5. Nandini NS. New insights into improving the oral health of visually impaired children. J Indian Soc Pedod Prev Dent 2003;21(4):142-143.

6. Krishna Kumar R, Fareed N, International Journal of Scientific Study. The effectiveness of oral health education program with and without involving self-maintainable oral hygiene skills among the visually impaired children.

7. Al-Sinaidi A. Oral hygiene practices and periodontal health status of visually impaired Saudi adults in Riyadh, Saudi Arabia. Pak Oral Dent J 2013;33(1):82-86.

8. Chang CHS, Shih YH. Knowledge of dental health and oral hygiene practices of Taiwanese visually impaired and sighted students. J Vis Impair Blind 2004;98:289-303. DOI: 10.1177/0145482X0409800504.

9. Lim LP. Comparison of modes of oral hygiene instruction in improving gingival health. J Clin Periodontol 1996;23(7):693-697. DOI: 10.1111/j.1600-051X.1996.tb00595.x.

10. Mahoney EK, Kumar N, Porter SR. Effect of visual impairment upon oral health care: a review. British Dental Journal, vol. 204. Nature Publishing Group; 2008. pp. 63-67.
11. Mahantesha T, Nara A, Kumari PR, et al. A comparative evaluation of oral hygiene using braille and audio instructions among institutionalized visually impaired children aged between 6 years and 20 years: a 3 month follow-up study. J Int Soc Prev Community Dent 2015;5(Suppl 2):S129-S132.

12. Vyas $\mathrm{S}$, Nagarajappa S, Dasar PL, et al. Impact of comprehendible learning modes on oral health among visually impaired adults. Spec Care Dent 2018;38(5):271-280. DOI: 10.1111/scd.12313.

13. Khurana C, Tandon S, Chand S, et al. Effectiveness of oral health education program using braille text in a group of visually impaired children-before and after comparison trial. J Educ Health Promot 2019;8:50.

14. Chowdary PB, Uloopi KS, Vinay C, et al. Impact of verbal, braille text, and tactile oral hygiene awareness instructions on oral health status of visually impaired children. J Indian Soc Pedod Prev Dent 2016;34(1):43-47. DOI: 10.4103/0970-4388.175510.

15. Gautam A, Bhambal A, Moghe S. Effect of oral health education by audio aids, Braille and tactile models on the oral health status of visually impaired children of Bhopal city. J Oral Biol Craniofac Res 2018;8(3):168-170. DOI: 10.1016/j.jobcr.2017.03.002.

16. Emier BF, Windchy AM, Zaino SW, et al. The value of repetition and reinforcement in improving oral hygiene performance. J Periodontol 1980;51(4):228-234. DOI: 10.1902/jop.1980.51.4.228.

17. Yalcinkaya SE, Atalay T. Improvement of oral health knowledge in a group of visually impaired students. Oral Health Prev Dent 2006;4(4):243-253.

18. Fageeh HN, Mansoor MA. The effectiveness of oral hygiene instructions in sign language among hearing impaired adults in Saudi Arabia. Special Care Dentist 2020;40(1):41-48. DOI: 10.1111/scd.12428.

19. Ahmad MS, Jindal MK, Hashmi SH. Oral health knowledge, practice, oral hygiene status and dental caries prevalence among visually impaired students in residential institute of Aligarh. J Dent Oral Hyg 2009;1(2):22-26.

20. Doichinova L, Gateva N, Hristov K. Oral hygiene education of special needs children. Part 2:visually impaired children. Biotechnol Biotechnol Equip 2019;33:821-826. DOI: 10.1080/13102818.2019.1621207.

21. Legge GE, Madison C, Vaughn BN, et al. Retention of high tactile acuity throughout the life span in blindness. Percept Psychophys 2008;70(8):1471-1488. DOI: 10.3758/PP.70.8.1471.

22. Alary F, Duquette $M$, Goldstein $R$, et al. Tactile acuity in the blind: a closer look reveals superiority over the sighted in some but not all cutaneous tasks. Neuropsychologia 2009;47(10):2037-2043. DOI: 10.1016/j.neuropsychologia.2009.03.014.

23. Deshpande S, Rajpurohit L, Kokka VV. Effectiveness of braille and audio-tactile performance technique for improving oral hygiene status of visually impaired adolescents. J Indian Soc Periodontol 2017;21(1):27-31. DOI: 10.4103/jisp.jisp_149_17.

24. Bhor K, Shetty V, Garcha V, et al. Effect of oral health education in the form of braille and oral health talk on oral hygiene knowledge, practices, and status of 12'17 years old visually impaired school girls in Pune city: a comparative study. J Int Soc Prev Community Dent 2016;6(5):459-464. DOI: 10.4103/2231-0762.192938. 
Appendix 1:The questionnaire used to assess the knowledge of visually impaired subjects in the study

\begin{tabular}{|c|c|c|c|}
\hline Q. No. & Questions & Multiple choices & Correct answer \\
\hline 1. & How many times should you brush your teeth in a day? & $\begin{array}{l}\text { a. Never brushed the teeth } \\
\text { b. One time per day } \\
\text { c. Two times per day } \\
\text { d. Once or two times a week }\end{array}$ & c \\
\hline 2. & What color of toothbrush bristles is recommended? & $\begin{array}{l}\text { a. Any color with stripes } \\
\text { b. White color with plain texture } \\
\text { c. Any color with plain texture } \\
\text { d. Bright color with stripes }\end{array}$ & $d$ \\
\hline 3. & $\begin{array}{l}\text { What type of bristles are recommended in the } \\
\text { toothbrush? }\end{array}$ & $\begin{array}{l}\text { a. Toothbrush with any type of bristle (I never } \\
\text { noticed) } \\
\text { b. Toothbrush with soft bristles } \\
\text { c. Toothbrush with medium-hard bristles } \\
\text { d. Toothbrush with hard bristles }\end{array}$ & $\mathrm{b}$ \\
\hline 4. & $\begin{array}{l}\text { What type of toothpaste is recommended to prevent } \\
\text { tooth decay? }\end{array}$ & $\begin{array}{l}\text { a. Fluoride toothpaste } \\
\text { b. Desensitizing toothpaste } \\
\text { c. Anti-plaque toothpaste } \\
\text { d. Any type of toothpaste }\end{array}$ & a \\
\hline 5. & $\begin{array}{l}\text { Which is the correct recommended brushing tech- } \\
\text { nique? }\end{array}$ & $\begin{array}{l}\text { a. Keeping the toothbrush bristles parallel to the } \\
\text { tooth surfaces } \\
\text { b. Keeping the toothbrush bristles perpendicular } \\
\text { to the tooth surfaces } \\
\text { c. Keeping the toothbrush bristles at } 45 \text { degrees } \\
\text { to the tooth surfaces } \\
\text { d. Brushing teeth in all possible directions }\end{array}$ & $c$ \\
\hline 6. & How often should you replace your toothbrush? & $\begin{array}{l}\text { a. After } 3 \text { months } \\
\text { b. After } 6 \text { months } \\
\text { c. After } 1 \text { year } \\
\text { d. I do not know }\end{array}$ & a \\
\hline 7. & How many times should you use an interdental brush? & $\begin{array}{l}\text { a. Once per day } \\
\text { b. Two times per day } \\
\text { c. Once per week } \\
\text { d. I do not know (I have not heard about this type } \\
\text { of toothbrush) }\end{array}$ & $\mathrm{b}$ \\
\hline 8. & How many times should you floss your teeth? & $\begin{array}{l}\text { a. Once per day } \\
\text { b. Two times per day } \\
\text { c. Once per week } \\
\text { d. Once per month }\end{array}$ & a \\
\hline 9. & $\begin{array}{l}\text { What type of mouthwash should you use to reduce } \\
\text { dental plaque and gingivitis? }\end{array}$ & $\begin{array}{l}\text { a. Cosmetic mouthwash } \\
\text { b. Fluoride mouthwash } \\
\text { c. Therapeutic mouthwash } \\
\text { d. Any type of mouthwash }\end{array}$ & $c$ \\
\hline 10. & $\begin{array}{l}\text { How often should you visit your dentist for a general } \\
\text { dental check-up and oral prophylaxis? }\end{array}$ & $\begin{array}{l}\text { a. Once in } 3 \text { months } \\
\text { b. Once in } 6 \text { months } \\
\text { c. Once in a year } \\
\text { d. Do not visit any dentist unless you have any } \\
\text { dental problem }\end{array}$ & $\mathrm{b}$ \\
\hline
\end{tabular}


Contd...

\begin{tabular}{|c|c|c|c|}
\hline Q. No. & Questions & Multiple choices & Correct answer \\
\hline 11. & What type of diet is the least to cause tooth decay? & $\begin{array}{l}\text { a. Sugary foods with every meal like cake, pastry, } \\
\text { ice creams } \\
\text { b. Soft drinks with every meal like Coco Cola, Pepsi } \\
\text { c. Fruit juices after every meal } \\
\text { d. Fibrous fruits after every meal like apple, carrots, } \\
\text { salad }\end{array}$ & $d$ \\
\hline 12. & $\begin{array}{l}\text { What is the first step to brushing the teeth of a visually } \\
\text { impaired child? }\end{array}$ & $\begin{array}{l}\text { a. Explain to the child the importance of } \\
\text { brushing teeth } \\
\text { b. Give a flavored toothpaste to the child of their } \\
\text { own choice } \\
\text { c. Provide plenty of praise and encouragement } \\
\text { d. Always call a visual therapist assistant for } \\
\text { brushing the child's teeth }\end{array}$ & a \\
\hline 13. & $\begin{array}{l}\text { What is the reason for teeth sensitivity after routine } \\
\text { scaling by the dentist? }\end{array}$ & $\begin{array}{l}\text { a. The dentist removes the part of the tooth } \\
\text { while doing the scaling procedure } \\
\text { b. The dentist removes part of the gingiva while } \\
\text { doing the scaling procedure } \\
\text { c. The tooth becomes weak and breaks by itself } \\
\text { after the scaling procedure } \\
\text { d. Unwanted deposits are removed from root } \\
\text { surfaces, temporarily leaving teeth sensitive to } \\
\text { temperature change }\end{array}$ & $d$ \\
\hline 14. & $\begin{array}{l}\text { After using a mouthwash, how long should you wait } \\
\text { before drinking water or eating food? }\end{array}$ & $\begin{array}{l}\text { a. } 5 \text { minutes } \\
\text { b. Half an hour } \\
\text { c. } 2 \text { hours } \\
\text { d. I do not know }\end{array}$ & b \\
\hline 15. & $\begin{array}{l}\text { While using a mouthwash, for how long should you } \\
\text { swish the mouthwash around your teeth? }\end{array}$ & $\begin{array}{l}\text { a. Place inside the mouth and spit immediately } \\
\text { to avoid swallowing } \\
\text { b. } 30-60 \text { seconds } \\
\text { c. } 5 \text { minutes } \\
\text { d. I do not know }\end{array}$ & $\mathrm{b}$ \\
\hline
\end{tabular}

